\title{
LOS PRESUPUESTOS PARA UNA COHABITACIÓN POLITICA EN LA CONSTITUCIÓN PERUANA DE 1993
}

POR

CARLOS HAKANSSON NIETO ${ }^{1}$

\section{INTRODUCCIÓN}

La teoría constitucional entiende por un periodo de cohabitación a la necesaria coyuntura política por la que debe atravesar el Jefe de Estado cuando debe nombrar como jefe de gobierno a su opositor político. Esta institución nació en Francia y su práctica ha dado lugar a un veraz cumplimiento de la Forma de Gobierno de la V República: un Jefe de Estado con verdadero poder y un Primer Ministro conductor de la política de gobierno. El modelo francés tiene importancia en el Perú porque la Carta de 1993 permite, bajo determinadas circunstancias, un fortalecimiento de la institución del Jefe de Gabinete. A tal punto, que los medios de comunicación denominaron "cohabitación a la peruana" las veces que un Presidente de la República se ve en la necesidad de nombrar a un Primer Ministro que, en principio, no estaría llamado durante su mandato a participar, directa o indirectamente, de la conducción del gobierno.

${ }^{1}$ Doctor en Derecho (Universidad de Navarra), Profesor de Derecho Constitucional (Universidad de Piura). Titular de la Cátedra Jean Monnet de Derecho Constitucional Europeo. Mi agradecimiento a los profesores Edgar Carpio Marcos (Universidad de Lima) y David Dumet Delfín (Universidad de Piura). 
Nos preguntamos, ¿es viable una cohabitación en el Régimen Político peruano? Observamos que, si bien el modelo presidencialista bajo la Carta de 1993 permitiría un fortalecimiento de su Jefe de Gabinete, éste siempre se ejercería gracias a determinados presupuestos y circunstancias apremiantes que escapan a las disposiciones constitucionales formales ${ }^{2}$. Por eso, en el presente artículo compararemos el funcionamiento de la Cohabitación francesa con el Presidencialismo peruano para determinar si es no aplicable a nuestra realidad, además de conocer sus reglas de juego político.

\section{LA COHABITACIÓN POLÍTICA EN LA CONSTITUCIÓN FRANCESA}

Como hemos mencionado, en la Constitución francesa la titularidad de la Jefatura de Estado y de Gobierno recaen en dos personas distintas, pero ambos comparten ciertas cuotas de poder en el ejecutivo. Los principales rasgos de interés para nuestro trabajo los veremos a continuación.

\section{El Jefe de Estado francés}

El Jefe de Estado es denominado por la Constitución francesa como Presidente de la República, y desde la reforma constitucional de 1962 es elegido por sufragio directo y por mayoría absoluta ${ }^{3}$; su mandato es de cinco años y puede ser reelecto ${ }^{4}$. La elección por sufragio universal y directo otorgó al Presidente de la República una legitimidad análoga a la parla-

2 En este artículo denominamos, salvo alguna excepción, al Presidente del Consejo de Ministros (su nombre oficial en la Constitución peruana) como Jefe de Gabinete o Primer Ministro.

${ }^{3}$ Una polémica reforma; pues, el General DE GAULLE logró no hacer intervenir al Parlamento. El Jefe de Estado conocía que las cámaras eran contrarias a la modificación y para ello recurrió a la convocatoria de un referendurn véase un comentario al procedimiento del referendumen LATSCHA, Jacques: "Une réforme costitutionnelle nécessaire" en Revue Fran aise de Science Polintigrula66, págs. 1101-1114.

${ }^{4}$ Antes de la reforma constitucional de 1962, el Jefe de Estado francés era elegido por un colegio electoral. Es más, la doctrina, a los pocos meses de aprobada la Constitución de 1958 era contraria a una elección directa por sufragio universal; véase en DEBRÉ, Michel: "La nouvelle constitution" en Revue Fran aise de Science Politique, no 1, 1959, pág. 24; véase además WAHL, Nicholas: "Aux origines de la nouvelle consti- 
mentaria. Sin embargo, el Jefe de Estado no responde ante el Legislativo y posee unos poderes que lo alejan también de un presidencialismo puro. En efecto, varios de los actos del Jefe de Estado se realizan sin necesidad de refrendo ministerial: el nombramiento del Primer Ministro, la convocatoria a referendum, la disolución del Parlamento, determinadas facultades extraordinarias, los mensajes a las cámaras y el nombramiento de tres miembros del Consejo Constitucional ${ }^{5}$. Además de estas facultades no son menos importantes el nombramiento del Primer Ministro, su potestad reglamentaria y observación de las leyes ${ }^{6}$.

\section{El Primer Ministro francés}

El Jefe de Estado nombra al Primer Ministro7; sin embargo, la Constitución no le atribuye de manera expresa la prerrogativa de destituirlo. El artículo 8 de la Constitución se limita a mencionar que el Presidente "pondrá fin a las funciones del Primer Ministro cuando éste le presente la dimisión del Gobierno" ${ }^{8}$. El artículo 21 de la Constitución francesa establece que el Primer Ministro dirige la acción del Gobierno, es responsable de la Defensa Nacional, velará por la ejecución de las leyes, ejercerá la potestad reglamentaria y efectuará los nombramientos de cargos civiles y militares. Además, podrá delegar algunos poderes en los ministros y suplir al Presidente de la República en determinados actos. De acuerdo con la Constitución, el Presidente de la República también propone a los ministros. El Primer Ministro dispone de la administración y de las fuerzas armadas. Además, comparte la iniciativa legislativa con los miembros del Parlamento ${ }^{9}$, así como la iniciativa de la refor-

${ }^{5}$ Art. 19 Constitución francesa de 1958.

${ }^{6}$ Véase el artículo 10 de la Constitución francesa de 1958.

${ }^{7} \mathrm{~A}$ diferencia de la Forma de Gobierno peruana, la elección del Ejecutivo y Legislativo no son coincidentes. Mientras que el Presidente de la República francés es elegido para un periodo de siete años, la Asamblea Nacional es elegida cada cinco, lo cual puede dar lugar a la formación de distintas mayorías.

${ }^{8}$ No obstante, en la práctica, si el Primer Ministro pertenece al mismo partido político del Jefe de Estado francés, el Presidente de la República podría, por su ascendiente, pedir la dimisión del Gobierno, véase TAJADURA TEJADA, Javier: La $V$ Rep blica FrancesaÉUNSA, Pamplona, 1997, pág. 84. 
ma constitucional ${ }^{10}$. Asimismo, puede plantear la responsabilidad del Gobierno ante el Parlamento con respecto a una declaración de política general o a la votación de un texto ${ }^{11}$.

$$
* * *
$$

Si bien es cierto que un Parlamento alberga todos los partidos políticos que han alcanzado el derecho a tener una representación nacional o regional, no podríamos decir lo mismo de la función ejecutiva, ya que, en principio, ella debería estar presidida por el candidato del partido que haya alcanzado la primera mayoría. No obstante, el semipresidencialismo francés creó una excepción a la regla: el periodo de cohabitación. Su origen no estuvo previsto en la Constitución francesa sino que se debió más bien a una coyuntura política que fue gestándose, paulatinamente, desde el nacimiento de la Carta de 1958. A continuación ofrecemos un resumen de la evolución política de esta institución.

\section{La práctica constitucional de 1959 a 1986}

Como hemos expuesto, la Constitución de 1958 atribuye importantes poderes al Primer Ministro para que pueda llevar a cabo su plan de gobierno. Sin embargo, antes de 1986, los artículos de origen parlamentarista no se observaban en la práctica política. El Primer Ministro era más bien el portavoz del Presidente de la República y ejecutor de su política. Sí la Constitución establecía que el Gobierno era responsable ante la Asamblea Nacional.

Durante la etapa de DE GaULLE (1959-1969) hubo una preeminencia del Jefe de Estado sobre el Gobierno ${ }^{12}$. Por su parte, los sucesores de DE Gaulle -Georges Pompidou, Valéry Giscard, d' Estaing y Francois MITTERRAND- confirmaron su voluntad de seguir asumiendo su papel protagónico en la $V$ República. En resumen, fueron dos los factores que acentuaron esta práctica: la elección del Presidente de la República mediante

\footnotetext{
${ }^{10}$ Art. 89.

${ }^{11}$ Art. 49.

12 DOGAN, Mattei: "El poder carismático en Francia» en Revista de Estudios Pol ticono 141-142, 1965, págs. 55-77; véase además ELGIE, Robert: "The French Presidency: conceptualizing presidential power in the Fifth Republic" en Public
} 
sufragio universal ${ }^{13}$, una mayoría parlamentaria que apoyaba la política del Presidente de la República, y un Primer Ministro nombrado por este sin una mayoritaria oposición parlamentaria ${ }^{14}$. El Primer Ministro no podía nombrar a su Gabinete, la política internacional y la defensa formaban parte del dominio reservado del Jefe de Estado de acuerdo con la Constitución. Si el Presidente de la República retiraba su confianza al Primer Ministro, este debía presentar su renuncia inmediatamente. Esta práctica de la dimisión-destitución, instaurada en 1962 y que fue confirmada y multiplicada en 1968, 1972 y 1984, manifiesta la subordinación del Primer Ministro al Presidente de la República. En resumen, cuando el Jefe de Estado y de Gobierno francés pertenecen a un mismo partido político, el nombramiento del Primer Ministro no plantea problema ${ }^{15}$. No obstante, ¿qué sucede cuando el Jefe de Estado francés no cuenta con mayoría en el Parlamento? En ese caso, el Jefe de Estado sólo tiene tres opciones ${ }^{16}$ :

${ }^{13}$ Sobre este punto notamos una división en la doctrina francesa. Para JEANNEAU la elección del Jefe de Estado francés por sufragio universal dota a esta magistratura de una legitimidad democrática tal que imposibilita el que un Jefe de Gobierno, incluso sostenido por una mayoría parlamentaria favorable, se atreva a imponer su programa. La única solución política a esta situación sería una reforma constitucional que corrigiera los desajustes del sistema provocados por la reforma de 1962; véase JEANNEAU, B: Droit Constitutionnel et Institutions PolDalioniBarís, 1972, pág. 240; en el mismo sentido véase además HAURIOU, André: Derecho Constitucional e Instituciones Pol ticaAriel, Barcelona, 1971, pág. 255.

${ }^{14}$ En ese sentido, HidALgo LAVIÉ nos dice que por más que las funciones del Primer Ministro estén reguladas en la Constitución francesa, la influencia que ejerce el Jefe de Estado sobre el de gobierno difícilmente puede ser contabilizada si el Presidente de la República goza de mayoría parlamentaria; véase HIDALGO LAVIÉ: "Una revisión de la noción semipresidencial...", págs. 7-8. Sin embargo, no todos los semipresidencialismos funcionan igual, pues los países sin mayoría parlamentaria evitan las tendencias extremas y alcanzan mayor coincidencia entre las relaciones ejecutivo-legislativo descritas en la Constitución y la práctica política.

${ }^{15}$ En ese sentido, ColliARD nos dice que la capacidad de gobernar del Jefe de Estado francés varía en la medida que tenga o no mayoría propia en el Parlamento; véase COLLIARD, Jean Claude: “Que peut le président?» en Pouvoirsn ${ }^{\circ}$ 68, 1994, págs. 22-28.

16 Para BuRdeAu, en 1976, fecha de la segunda edición de su tratado, no se planteó una situación de antagonismo entre ejecutivo y legislativo; sino el que dentro de una orientación política similar el Parlamento posea o no capacidad para negociar la investidura del Primer Ministro; véase BURDEAU, Georges: Trat de Science Poli tótumeen 9, LGDJ, Paris, 1976, págs. 348 y sigs. Es a partir de la Legislatura de 1978, ante una posible victoria de la izquierda bajo el mandato del Presidente Giscard, cuando la doctrina se preocu- 
1 Disolver la Asamblea Nacional.- El Jefe de Estado podría disolver la Cámara baja, la Constitución francesa lo permite, pero consideramos que no sería oportuno ya que el electorado puede confirmar, y con creces, su decisión de otorgarle mayoría parlamentaria a la oposición política.

2. Nombrar como Primer Ministro a un miembro de su partido con todas sus consecuencias. - En efecto, la Asamblea Nacional podría abstenerse de votar las normas que le someta el Ejecutivo, puede también negarse a otorgarle el apoyo que requiere la aplicación de su política, o puede censurarlo en los términos del artículo 49 de la Constitución francesa.

3. Nombrar a su Primer Ministro entre la mayoría adversa.- Es decir, elegirá a un Jefe de Gobierno decidido a aplicar una política diferente a la que desea el Jefe de Estado. Así ocurrió en 1986, tras el triunfo en las urnas de la coalición de centro-derecha que lideraba CHIRAC y que inauguró lo que se ha llamado la República de la cohabitación ${ }^{17}$.

\section{La práctica de la cohabitación}

El término "cohabitación" no se encuentra en la Constitución francesa de 1958. En resumen, consiste en que el ejecutivo pasa a ser bicéfalo; es decir, un Jefe de Estado elegido por sufragio directo y un Jefe de Gobierno del agrado de la oposición política; ambos con sendas funciones establecidas por la propia Constitución. Como podemos apreciar, la Asamblea Nacional cumple la función de un péndulo, es decir, triunfará la política del Presidente o del Primer Ministro cuando uno u otro conserven su mayoría en el Legislativo.

De esta manera, la Forma de Gobierno francesa se aplica como fue prevista literalmente en la Carta de 1958 cuando la mayoría que apoya al Primer Ministro es de signo político contrario a la del Presidente de la

${ }^{17}$ En 1967, antes de las elecciones legislativas, algunos dirigentes políticos declararon que si la composición de la nueva Asamblea no permitía la constitución de una mayoría de Gobierno favorable a la política presidencial, la Asamblea Nacional debería ser disuelta y en caso de que los electores persistieran en otorgar su confianza a la oposición, el Presidente debería aplicar el artículo 16 y gobernar prescindiendo de la Asamblea. Es evidente que la interpretación de este artículo es contraria al espíritu constitucional porque supone un golpe de estado. 
República ${ }^{18}$. En ese momento el Jefe de Estado comienza a actuar dentro del marco fijado por el artículo 5 de la Constitución de 1958. Al aplicarse la Constitución, el Jefe de Estado no sólo no podrá exigir la dimisión del Jefe de Gobierno sino que deberá aceptar el Consejo de Ministros que éste le proponga. Tampoco podrá recurrir discrecionalmente al referendo y, sobre todo, será el Primer Ministro quien conduzca la política del Gobierno conforme al artículo 20. El Jefe de Estado, en cambio, sólo podrá pedir una nueva deliberación de los proyectos de ley ${ }^{19}$, podrá negarse a firmar ciertas ordenanzas y decretos ${ }^{20}$, podrá oponerse a nombramientos en los empleos, superiores civiles y militares, entre otras atribuciones.

En la actualidad, tanto el Primer Ministro como el Presidente de la República francés han aceptado la "cohabitación». JACoues ChABAN-DeLMAS dijo que es "una coexistencia forzosa en la que cada uno vigila al otro.... ${ }^{21}$. En la práctica constitucional francesa ninguno de ellos ha manifestado la intención de ponerle fin, porque en la realidad ambos saben que su actitud sería reprobada por el electorado. Finalmente, consideramos que la Forma de Gobierno francesa no se convierte en un modelo parlamentarista cuando el Jefe de Gobierno tenga mayoría en la Asamblea Nacional, porque el Presidente conserva, con o sin cohabitación, importantes facultades. De la misma manera, cuando el Jefe de Estado tiene dicha mayoría, tampoco creemos que sea más presidencialista, porque sus poderes no son propios de un presidencialismo puro, aunque se encuentra más cerca al modelo iberoamericano.

$* * *$

Hasta aquí hemos expuesto las líneas generales de un periodo de cohabitación en la Constitución francesa. Debemos preguntarnos ahora si la Forma de Gobierno peruana admite esta coyuntura política o si es posible aproximarnos a ella mediante una convención constitucional. Para lograrlo,

18 Por el contrario, fuera de los períodos de cohabitación, ELGIE Y MACHIN consideraban como una paradoja que en la Constitución de 1958 las atribuciones del Jefe de Gobierno eran asumidas por el Jefe de Estado; véase ELGIE, Robert; MACHIN, Howard: "France: The limits to Prime-Ministerial Government in a Semi-Presidential System» en West European Prime Minista오, 1991, pág. 62.

${ }^{19}$ Art. 10 Constitución francesa de 1958.

${ }^{20}$ Art. 13.

${ }^{21}$ AVRIL, Pierre; GICQUEL, Jean: "Chronique constitutionnelle francaise», Pouvoirs, no 39, Paris, 1986, págs. 161-170. 
es conveniente que comparemos el modelo francés con el peruano.

\section{LOS PRESUPUESTOS PARA UNA COHABITACIÓN POLÍTICA EN LA CONSTITUCIÓN PERUANA}

Si bien los constituyentes tuvieron presente la Constitución francesa de 1958, también es cierto que no desearon un modelo semipresidencialista sino todo lo contrario: fortalecer los poderes del Presidente de la República ${ }^{22}$. Un repaso a las diferencias entre ambos modelos saltarán a la vista. No obstante, no vamos a detenernos en la explicación detallada de las funciones administrativas del Presidencia del Consejo de Ministros, porque no es el objetivo de este trabajo profundizar en el estudio de esta institución.

\section{Las competencias del Presidente de la República y del Jefe de Gabinete}

Como sabemos, en el régimen presidencialista los cargos de Jefe de Estado y de Gobierno recaen en un mismo titular: el Presidente de la República. Sin embargo, el modelo Presidencialismo peruano cuenta con un Presidente del Consejo de Ministros ${ }^{23}$. Un Jefe de Gabinete que posee unas concretas atribuciones, las cuales pueden verse "enriquecidas" de acuerdo con determinadas coyunturas políticas. A continuación expondremos primero las principales competencias del Presidente de la República, en su calidad de Jefe de Estado y de Gobierno, y a continuación la atribuciones conferidas a su Jefe de Gabinete.

\subsection{Las atribuciones presidenciales como Jefe de Estado}

La calidad de Jefe de Estado del Presidente de la República la encon-

\footnotetext{
22 Véase PLANAS SILVA, Pedro: Democracia y Tradici n Constitucional en el Per, San Marcos, 1998, págs. 70-72. «En la Asamblea Constituyente de 1978-1979 (...) a nadie en ningún momento (...) se le ocurrió crear un Premier al modelo europeo, sino por el contrario, se planteó un presidencialismo fuerte, más acentuado aun del que aflora en la Constitución de 1933, precisamente para evitar los desbordes incurridos por el Legislativo en los períodos 1945-1948 y 1963-1968. Lo que sí fue objeto de un debate; aun cuando corto, fue cierta propuesta de introducir en nuestro medio, la diarquía constitucional francesa en la cual existe un Jefe de Estado al lado de un Jefe de Gobierno"; cfr. GARCÍA BELAUNDE, Domingo: «El Presidente del Consejo de Ministros en la nueva Constitución" en Teor a y Pr ctica de la Constituci n Ptormonlą EDDILI, 1989, Lima, pág. 155.

${ }^{23}$ En este trabajo utilizaremos los términos "Primer Ministro" y "Jefe de Gabinete»
} 
tramos en el artículo 110 de la Constitución, y sus principales competencias se encuentran en el artículo 118. En este artículo nos ocuparemos solamente de aquellas que sean de interés para nuestro trabajo.

a) Pol tiea Bestacamos dos importantes funciones, su facultad de convocar al Parlamento de manera extraordinaria y su facultad para nombrar embajadores.

b) Cuasi judiciales Entre las funciones cuasi judiciales del Presidente de la República como Jefe de Estado distinguimos su facultad para ejecutar las sentencias, conceder el indulto y para interponer una acción de inconstitucionalidad ante el Tribunal Constitucional.

c) LegislatitaEl Jefe de Estado se encarga de promulgar y vetar las leyes.

d) De defensa En primer lugar tiene el cargo de Jefe Supremo de las Fuerzas Armadas y, en consecuencia, puede adoptar las medidas necesarias para la defensa de Estado así como también decretar los estados de excepción.

\subsection{Las atribuciones como Jefe de Gobierno}

El artículo 118 de la Constitución peruana establece las competencias más importantes del Presidente de la República en relación a la jefatura de gobierno. Para empezar, nos dice que dirige la política general del gobierno ${ }^{24}$, administra la hacienda pública ${ }^{25}$, negocia empréstitos ${ }^{26}$ y regula las tarifas arancelarias ${ }^{27}$. Por otro lado, la ley del Poder Ejecutivo establece que el Primer Ministro colabora con el Presidente de la República en la dirección gobierno ${ }^{28}$.

a) PoI tica匢 Presidente de la República como Jefe de Gobierno tiene la facultad de nombrar y remover a los ministros, así como presidir las sesiones del Gabinete cuando asiste a sus reuniones ${ }^{29}$. La Constitución

${ }^{24}$ Art. 118. 3 Constitución peruana de 1993.

${ }^{25}$ Art. 118. 17.

${ }^{26}$ Art. 118.18.

${ }^{27}$ Art. 118. $20 .{ }^{28}$ Art. 14 de la Ley del Poder Ejecutivo, Decreto Legislativo no 560 de 1990.

${ }^{29}$ Debe concordarse con el artículo segundo de la ley de ministros de 1862.

${ }^{30}$ Art. 122 Constitución peruana. 
establece que puede nombrar y remover al Jefe de Gabinete así como a los demás ministros, a propuesta y con acuerdo de éste ${ }^{30}$.

La redacción de este artículo es similar al artículo 8 de la Constitución francesa ${ }^{31}$. Sin embargo, en la práctica, el Presidente peruano tiene más libertad para nombrar a su Jefe de Gabinete que el Jefe de Estado francés para nombrar a su Primer Ministro ${ }^{32}$, pues este último puede verse en la necesidad de nombrar al líder de la oposición si no cuenta con mayoría en la Cámara Baja 33 .

La Constitución peruana permite al Presidente de la República escoger a sus ministros del Parlamento ${ }^{34}$, una elección incompatible con el Presidencialismo norteamericano, donde el separación de poderes es más tajante. De igual manera, en la Constitución francesa son incompatibles las funciones de miembro del gobierno con el ejercicio de cualquier mandato parlamentario, y con cualquier función de representación de carácter nacional y cualquier actividad profesional ${ }^{35}$. Es decir, a pesar de tratarse de un semipresidencialismo, se respeta más la separación de poderes que en la Forma de Gobierno peruana.

El Presidente de la República dirige la política general del Ejecutivo, dentro de los márgenes de maniobra que le permiten los grupos de presión y el Parlamento, si no cuenta con mayoría propia. No olvidemos que se trata de un irresponsable político y son los ministros quienes asumen la responsabilidad; por ese motivo, la Constitución peruana establece que no hay ministros interinos ${ }^{36}$.

${ }^{31}$ El artículo 8 de la Constitución francesa de 1958 establece que «el Presidente de la República nombra al Primer Ministro. Pone fin a sus funciones al presentar este último la dimisión del gobierno".

32 No obstante, el poder del Primer Ministro peruano puede variar en la práctica, según la fuerza de su personalidad y su relación con el Presidente; en el mismo sentido véase a McCLINTOCK: "Presidentes, mesías políticos y crisis constitucionales en Perú», en LINZ, Juan, VALENZUELA, Arturo, Las crisis del presidencialismo. El caso de Latinoam ricæolumen 2, Alianza, Madrid, 1998, pág. 290.

${ }^{33}$ Cabe destacar que por influencia francesa se introdujo en el derecho constitucional peruano el uso del vocablo «Premier» como sinónimo de presidente del consejo de ministros.

${ }^{34}$ Art. 126 Constitución peruana de 1993.

35 Art. 23 Constitución francesa de 1958.

${ }^{36}$ El artículo 127 establece que «el Presidente de la República puede encomendar a un ministro que, con retención de su cartera, se encargue de otra por impedimento del que la sirve, sin que este encargo pueda prolongarse por más de treinta días ni trasmi- 
El artículo 121 de la Constitución peruana establece la atribución del Presidente de la República para presidir el Gabinete cuando lo convoca o asiste a sus sesiones ${ }^{37}$. Esta disposición parece inspirada en la Forma de Gobierno de la Constitución francesa, ya que, si bien el Jefe de Estado preside el Consejo de Ministros ${ }^{38}$, el Primer Ministro puede suplirlo en virtud de una delegación expresa y con un orden del día determinado ${ }^{39}$.

b) LegislativasEl Presidente de la República peruano goza de dos facultades que lo distinguen del Presidente estadounidense: tiene expresa facultad legislativa mediante una ley de autorización parlamentaria y también puede dictar decretos de urgencia. La Constitución peruana le confiere reglamentar las leyes ${ }^{40}$ y expedir decretos legislativos, decretos supremos y resoluciones supremas ${ }^{41}$. Por influencia de la Constitución francesa, el Presidente de la República tiene expresa iniciativa legislativa vía decretos legislativos, gracias a una ley autorizadora del Parlamento ${ }^{42}$.

La facultad legislativa del Presidente de la República se extiende a la producción de los Ilamados decretos de urgencia ${ }^{43}$. Es una atribución ya establecida en la Constitución de 1979, que podría considerarse como una manifestación de la facultad legislativa del ejecutivo ${ }^{44}$. Finalmente, la Constitución dispone que si el Presidente de la República disuelve del Congreso de acuerdo con la Constitución ${ }^{45}$, gobierna mediante decretos de urgencia hasta la elección y configuración del nuevo legislativo.

${ }^{37}$ El artículo 15 de la Ley del Poder Ejecutivo establece, de la misma manera, que el Primer Ministro preside el Consejo de Ministros «cuando el Presidente de la República no asista a sus sesiones".

${ }^{38}$ Art. 9 Constitución francesa de 1958.

39 Art. 21.

40 Art. 118. 8 Constitución peruana de 1993.

${ }^{41}$ Art. 3 Ley del Poder Ejecutivo.

42 El artículo 38 de la Constitución francesa de 1958 establece que «el gobierno podrá, para la ejecución de su programa, solicitar autorización del Parlamento para adoptar, por vía de decretos, durante un plazo limitado, medidas normalmente pertenecientes al dominio de la ley. Los decretos serán expedidos en consejo de ministros previo dictamen del Consejo de Estado".

${ }^{43}$ Art. 118.19 Constitución peruana de 1993.

${ }^{44}$ Art. 211.20.

${ }^{45}$ Art. 134 Constitución peruana de 1993. 


\subsection{E1 Jefe de Gabinete}

En la Constitución peruana, el Jefe de Gabinete es denominado Presidente del Consejo de Ministros ${ }^{46}$ que, junto con el Presidente de la República, colabora en la dirección de la política general ${ }^{47}$. La Constitución peruana - a diferencia de su antecesora de 1979- establece sus funciones; el artículo 123 nos dice que es el portavoz oficial de la Presidencia de la República, coordina el trabajo del gabinete, y que tiene la competencia para refrendar determinados actos del Ejecutivo.

El Primer Ministro peruano es un primus inter pa48eque, en principio, no posee las características de un Primer Ministro como el francés ${ }^{49}$. Al respecto, GaRCía BELAUNDE considera que si alguna preeminencia puede tener el Jefe de Gabinete será como resultante de su propia habilidad, de su propio quehacer político, o del éxito de su gestión personal ${ }^{50}$.

$$
* * *
$$

Para finalizar este apartado, hemos apreciado que la acumulación de atribuciones que posee el Presidencia de la República en un modelo presidencialista dificultaría, en principio, un proceso de cohabitación al estilo de la Constitución francesa. No obstante, la práctica del Derecho Constitucional nos ha mostrado que es posible la creación de un conjunto de "hilos invisibles" que permitan, en concretas circunstancias políticas,

46 En la Constitución peruana encontramos muchos "presidentes», primero el Presidente de la República, que debía ser el único así denominado, luego el Presidente del Consejo de Ministros y por último el Presidente del Congreso.

${ }^{47}$ Art. 14 Ley del Ejecutivo.

${ }^{48}$ En el mismo sentido véase GARCÍA BELAUNDE: "El Presidente del Consejo de Ministros...", pág. 257; véase además FERNÁNDEZ SEGADO: "Las relaciones entre los órganos de gobierno en la Constitución del Perú: un modelo híbrido entre el presidencialismo y el parlamentarismo", en Derecho, no 42-43, 1990, pág. 168.

${ }^{49}$ En ese sentido García BeLAúnde nos dice que en la asamblea constituyente de 1979 "lo que sí fue objeto de debate (...) fue cierta propuesta de introducir en nuestro medio, la diarquía constitucional francesa, en la cual existe un jefe de estado al lado de un jefe de gobierno. Pero hay que recalcar que esta iniciativa no sólo no prosperó sino que por el contrario, fue reafirmado el carácter presidencial de nuestro sistema constitucional»; cfr. GARCÍA BELAUNDE: "El Presidente del Consejo de Ministros...", pág. 155.

${ }^{50}$ Véase GARCÍA BELAUNDE: «El Presidente del Consejo de Ministros...», pág. 158. 
una delegación de funciones hacia su Jefe de Gabinete. Sin embargo, a nuestro entender, todavía sería precipitado denominar como cohabitación a este fenómeno por el resto de argumentos que expondremos en este trabajo:

\section{2. ¿Cabe un periodo de cohabitación en la Constitución peruana?}

Consideramos que no es posible que el Régimen Político peruano admita un ejecutivo bicéfalo. No obstante, VILLARÁn sostuvo que no era viable en ninguna forma de gobierno contemporánea ${ }^{51}$. Sostenía que el "gobierno de "dos Presidentes" semejante al régimen de los cónsules en Roma, un Presidente de la República y un Presidente del Consejo de Ministros, ambos responsables y con política propia, que sugiere HAORIOU para corregir los defectos del parlamentarismo en Francia, es inverosímil que funcione con éxito en ningún país moderno. En el Perú es inconcebible. La unidad de acción, la orientación política del Poder Ejecutivo, en nuestro sistema de gobierno, corresponde de hecho y de derecho al Presidente de la República» ${ }^{52}$.

Las principales observaciones que debemos tener en cuenta antes de proponer un periodo de cohabitación en la Constitución peruana serían las siguientes:

\subsection{Las elecciones Ejecutivo-Legislativo son generales}

En Francia, la cohabitación se produce cuando el partido del Jefe de Estado pierde su propia mayoría en la Asamblea Nacional. En el Perú no necesariamente. Recordemos que en la Constitución peruana no hay renovación parlamentaria a mitad de mandato. Los periodos son fijos. Es decir, las elecciones del ejecutivo y legislativo son separadas y no coincidentes. En el modelo peruano, a diferencia de la Constitución norteamericana y la gran mayoría de los países iberoamericanos, el Presidente de la República puede o no ser elegido conjuntamente con una clara mayoría, la cual será mantenida durante todo su mandato sin posibilidad de renovación a la mitad del periodo presidencial. En ese sentido, las posibilidades de una

51 Un error, dado que el Profesor MANUel ViCente VilLaRÁn no conoció la Constitución francesa de 1958 debido a que falleció ese mismo año; además, la primera cohabitación política en Francia se produjo en 1986.

52 Véase VILLARÁN, Manuel Vicente: Posici n constitucional de los ministros en el 
cohabitación por un repentino cambio de mayoría parlamentaria no se producirían en el Régimen Político peruano.

\subsection{El multipartidismo en el Parlamento peruano}

Un periodo de cohabitación al estilo francés requiere, necesariamente, de un sistema de partidos del cual carece la Forma de Gobierno peruana. La regla "a mayor representatividad menor gobernabilidad", sugiere un Parlamento bicameral con no más de cuatro partidos políticos en una Cámara Baja ${ }^{53}$. De lo contrario, es probable que una oposición mayoritaria esté de acuerdo en proponer un cambio de Jefe de Gabinete, pero difícilmente convendrán en sugerirle un Primer Ministro sustituto al Presidente de la República.

Si bien esta no es la oportunidad para proponer la estructura de un sistema de partidos en el Perú, podemos adelantar que ésta debería ser conformada como máximo por cuatro agrupaciones políticas. Dos partidos políticos de gran representatividad parlamentaria y dos coaliciones cuyos titulares y composición podrían renovarse periódicamente de acuerdo con los vientos favorables del electorado.

3. No existe en la Constituci n peruana una formal divisi $n$ de funciones en las tareas de gobierno

Como explicamos, en la Forma de Gobierno peruana el titular del Ejecutivo es el Presidente de la República. El artículo 118 de la Constitución sólo le confiere a él las atribuciones. El Jefe de Gabinete lo acompaña en la conducción del gobierno. En ese sentido, la Carta peruana de 1993 es más clara que su antecesora de 1979, por establecer las competencias que se le confieren a esta institución (ser el principal portavoz del gobierno después del Presidente, refrenda determinados actos, y coordina el trabajo del gabinete). En ninguna de ellas se le atribuyen verdaderas atribuciones de gobierno al Jefe de Gabinete. Nos encontramos con un ministro que vendría a ser un primus inter parłesomo establece la propia Carta de 1993, el principal portavoz del Gobierno después del Presidente de la República, principal coordinador de los demás ministros, y que refrenda determina-

53 En el mismo sentido, véase SARDÓN, José Luis: La Constituci $n$ incompleta, Instituto Apoyo, 1999, pág. 102. 
dos actos del Jefe de Estado. Sin embargo, en la práctica política, el Presidente del Consejo de Ministros va asumiendo una importante labor de apoyo, sobre todo la de desviar las críticas dirigidas por la oposición hacia la Presidencia de la República.

\section{La flexibilidad del Presidencialismo peruano}

Como mencionamos, en determinadas circunstancias políticas, cuando el Presidente de la República es elegido con una frágil representación parlamentaria, es decir, poseedor de una mayoría simple pero no absoluta de parlamentarios provenientes de su partido político, la estabilidad de la presidencia de la República podría verse afectada sin una sólida conducción del gobierno; el Jefe de Estado podría nombrar a un mejor «intermediario» con el Parlamento. No obstante, esa decisión no supone necesariamente un cambio de política, ni de ideología partidaria. En esos casos, el Presidente de la República no se ve en la necesidad de nombrar al líder de la oposición parlamentaria, como ocurre en Francia, sino a un outsidede la política, un ex ministro reconocido, un político con trayectoria democrática, o quizá a un parlamentario de oposición, de reconocido prestigio y con minoría en el Congreso. Una buena oportunidad para un joven político, dado que se mostraría como estadista ante el electorado sin correr el riesgo del eventual desgaste que correría el líder de la oposición en la presidencia del Consejo de Ministros. Hay que aclarar que estas fórmulas eran impensables bajo el régimen político de las constituciones peruanas de fines del siglo $\mathrm{XIX}^{54}$.

\section{La delegaci n de funciones por el Presidente de la Rep blica}

El panorama actual ha cambiado en comparación a las opiniones que VILLARÁN formulara sobre el Jefe de Gabinete en el Perú. El profesor sostenía que "lo usual no es que el Jefe de la Nación se adhiera a la política que le propone el organizador del Gabinete, sino que el Presidente busque para organizarlo a un hombre que piense como él y que se adhiera a su política. Ha habido Presidentes del Consejo que han tenido gran influjo sobre el ánimo del primer magistrado $y$, a través de éste, han ejercido cierta acción directiva, más o menos visible, sobre los otros ministros; pero éstos no ven en el Presidente del Consejo más que un Ministro igual

\footnotetext{
54 Véase VILLARÁN: Posici n constituciorpálg. .59,

${ }^{55}$ VILLARÁN: Posici n constitucionapág.57..,
} 
a ellos, y no están dispuestos a permitir que traspase los linderos de lo que estiman su jurisdicción independiente ${ }^{55}$. En ese sentido, el Jefe de Gabinete quizá no tendrá la posibilidad de nombrar a su propio Consejo de Ministros, así como tampoco determinar la política del Estado peruano; sin embargo, mientras que en la Constitución francesa se aplican los artículos relativos a las competencias del Primer Ministro, en el Perú se espera que el Presidente de la República "delegue», en la práctica política, las atribuciones de la jefatura de gobierno a favor de un Primer Ministro que, en principio, no goza de esas facultades por la Constitución de 1993.

De esa manera, el Primer Ministro formará su gabinete y refrendará los actos del Presidente; unos actos que, irónicamente, él mismo ha decidido; con lo cual se produciría una mutación constitucional en el refrendo, que pasa de una institución que otorgaba legalidad a los actos del Presidente de la República a convertirse, en la práctica, en un acto que otorga legalidad a las funciones del Primer Ministro como Jefe de Gobierno, dado que esos actos son consentidos por el Presidente de República. Si bien la delegación de atribuciones no está reglamentada por la Constitución, consideramos que la institución del refrendo será de gran importancia y adquirirá una dinámica distinta.

\section{CONCLUSIÓN}

Al finalizar este artículo sólo nos queda afirmar que el Régimen político peruano no admite una cohabitación política al estilo francés. Resumidamente, las razones que encontramos son las siguientes:

A) A diferencia de la Constitución francesa, la titularidad de las jefaturas de estado y de gobierno en la Forma de Gobierno peruana recaen en el Presidente de la República.

B) Las elecciones al Parlamento y Gobierno son coincidentes; además, los mandatos son fijos y con la misma duración (cinco años).

C) La ausencia de un sistema de partidos que sea estable y con eficaces barreras electorales.

D) La previsible negativa del líder de la oposición parlamentaria a cambiar su posición fiscalizadora hacia una conducción del Ejecutivo, sin la legitimidad que proporciona una contundente victoria en las elecciones democráticas.

No obstante, en el límite de determinadas circunstancias políticas, el 
Presidente de la República puede recurrir a la figura de un «miembro no previsto en su gobierno" para nombrarlo como su principal portavoz, intermediario ante el Parlamento y los medios de opinión. En ese sentido, las atribuciones del Jefe de Gabinete descritas en la Constitución peruana permiten un mayor grado de actuación política. Es decir, pueden llevar a un fortalecimiento en la actuación del Jefe de Gabinete al punto de casi asumir las decisiones, coordinación y dirección del Ejecutivo, nombrando quizá con tiempo a su propio Consejo de Ministros, hasta que las causas que explicaron su nombramiento disminuyan o cesen para evitar "la creación un candidato presidencial». Por tanto, más que ante un gobierno de cohabitación a la francesa, que implica determinar la política nacional y capacidad de nombrar a un gabinete, estaremos ante un Primer Ministro de "emergencia" o "coyuntura", cuya permanencia en el Ejecutivo guardará relación con las circunstancias que motivaron su nombramiento por el Presidente de la República. 